\title{
Are Regulatory Agencies Independent in Practice? Evidence from Board Members in Spain
}

\author{
Xavier Fernández-i-Marín ${ }^{11}$ \\ Jacint Jordana ${ }^{22}$ \\ Andrea C. Bianculli ${ }^{33}$
}

1 1. Contact author. ESADEgeo (Center for Global Economy and Geopolitics), ESADE Business School.

\footnotetext{
2 2. Universitat Pompeu Fabra and Institut Barcelona d'Estudis Internacionals (IBEI)

3 3. Institut Barcelona d'Estudis Internacionals (IBEI)
} 


\begin{abstract}
Are the board members of regulatory agencies (regulators), taken as a particular cluster within the public sphere, independent of elected politicians and tenured bureaucrats? How can we assess their independence in practice, beyond formal rules? To address these questions, this paper delves into two key dimensions: board members' social connections and their security of tenure in office. First, we focus on regulators' identity as policy adjudicators and examine their political and administrative relations. In doing so, we expect to understand better how regulators' social and political situations may influence their behaviour. Secondly, we assess their political vulnerability through political cycles in order to measure their de facto independence over time. Additionally, variations in these two dimensions are compared with respect to the effect of different de jure appointment rules. We contrast these expectations with the empirical evaluation of board members of regulatory agencies in Spain (1979-2010). Thus, we confirm that regulators who have an administrative profile are more vulnerable to political changes than those with political ties, while appointment rules have an influence on their political vulnerability.
\end{abstract}


Keywords: regulatory agencies; regulatory governance, agency boards, independence, regulators' turnover

\section{Introduction}

Recently, regulatory institutions have significantly expanded worldwide. Focused on the implementation, supervision and promotion of regulatory policies, they are constituted in most cases as formally independent agencies. Whereas before the 1980s they remained circumscribed to particular sectors - namely, finance - during the last few decades they diffused across a wide range, including social policy and the public services (see interalia, Levi-Faur \& Jordana 2005, Christensen \& Lægreid 2006, Gilardi, Jordana \& Levi-Faur 2007, Gilardi 2008, Verhoest, Roness, Verschuere, Rubecksen \& MacCarthaigh 2010, Jordana, Levi-Faur \& Fernández-i-Marín 2011, Baldwin, Cave \& Lodge 2012).

Located at the top of the agencies, most often board members are those responsible for making decisions and for interpreting how existing laws should be applied and implemented. Though procedures to appoint agency board members vary a great deal across the world, it is fair to say that, democratically legitimated institutions appoint most regulators in liberal democracies. Only in a few cases are board members named by interest groups or professional associations involved in the regulatory sector. Regulators are seldom required to be bureaucrats or to have a political profile and/or expertise. In fact, often they are expected to have only specific professional qualifications and previous knowledge of the regulated sector. The question that comes next is whether regulators have an independent role in public policymaking; in particular, are they independent in practice? 
In this paper, we assess their role by looking into two key dimensions: regulators' social connections and whether they are politically vulnerable. That is, do they have security of tenure in office when governments change? Our main argument is that a measure of the links board members maintain with politicians and bureaucrats, on the one hand, and the extent to which they endure through political cycles, on the other, can together be used as a proxy for their de facto independence. We suspect that having or not having personal connections with elected politicians and traditional bureaucrats may lead to different patterns of behaviour and limit informal hierarchies and control their habits. Secondly, and to corroborate such differences, we assess the stability of regulators through political cycles, examining to what extent they survive the politicians responsible for their appointment and continue in office for the term for which they were appointed. We then look into the implications and the meaning of these different patterns. It may happen that removing a regulator with strong political ties to the opposition party after an electoral change would involve higher costs than removing one by referring only to a professional profile.

In defining a complex rationale for measuring independence, we provide a new framework for the analysis of board members taken as a particular cluster within the public sphere. By introducing a sophisticated conceptual and methodological perspective to study their independence, we expect to understand better the circumstances under which board members' distinctiveness and stability may influence the behaviour of agencies. The paper makes a unique contribution by distinguishing de jure from de facto independence of board members through the combination of different elements: data on the legally expected duration of an appointment (de jure) and its real length (de facto); biographical data of board members and organizational 
information on all regulatory agencies. These elements combine into a Rolling Adapted Index of Political Vulnerability (RAIPV) that allows a more precise estimate of the rate of renewal of regulators through time. It is our purpose thus to develop a more comprehensive analysis of the issue of independence in regulatory studies, including but moving beyond the use of the conventional proxy of dismissal risks during political changes, which has dominated the quantitative literature on this topic for years.

To test our expectations, the paper builds on a broad map of Spanish regulatory agencies across various sectors during 30 years. Moreover, the analysis focuses not only on agencies' heads, as has been usual in most studies, but on agencies' boards (which include the agency head). We assess variations in their identity and stability across the institutional design of regulatory agencies and reconstruct their profiles using a range of biographical data, together with the duration of their appointments for the period 1979 to 2010. By means of this reconstruction, the paper provides both static and dynamic pictures of regulators' careers in Spain. The high volatility of board members' appointments in Spain during most of the period examined makes this country an ideal case for exploring some behavioural mechanisms underlying the independence of regulators despite existing formal rules.

Our findings confirm that agencies' board members show different stability and vulnerability patterns according to their biographical profiles. Moreover, we find that those having an administrative profile are more sensitive to political changes than those with political ties. Additionally, we show that different de jure appointment rules impact on the political vulnerability of regulators, i.e. those appointed by the legislature enjoy greater de facto independence. These results also warn against simplistic interpretations of the determinants of independence 
and call for better formulated hypotheses of regulatory agencies' capabilities.

The paper is structured as follows. Section 2 presents the framework devised to analyse regulatory agencies' board members as a distinctive force in current political and policy processes. The following sections (3 and 4) introduce the methods and the dataset used. Results are the core of section 5 , followed by the conclusions in section 6 .

\section{A Framework for Examining the De Facto independence of Regulatory Agencies}

In recent decades, especially in the 1990s, most countries implemented a new institutional model within the executive branch: the independent regulatory agency. These agencies constitute administrative units responsible for the supervision, regulation and control of social and economic activities (Bianculli, Fernández-i-Marín \& Jordana 2013). Their "regulatory" character is based on the application and development of rules derived from general laws. Regulatory agencies work in a particular policy area (e.g. telecommunications) or on a specific economic or social problem (e.g. to guarantee market competition or to ensure data protection). More importantly, they share a common feature: the presence of mechanisms to delegate authority from the public authorities that established them to the agency, and in particular, to those within the agency responsible for making decisions: the regulators, whom we identify as the agency board members, including the agency head.

Formally the independence of regulators from the executive is frequently legally protected to the extent that the government cannot dismiss them during their term of office. Regulators rely hence on fixed-term mandates typically not coinciding with the executive term. 
Moreover, professional requirements are also commonly specified for heads and board members, together with the renewal conditions of their position. Nevertheless, regulators are not required to be tenured public servants on the government payroll. They can be hired because of their previous experience in the regulated policy area either in the private sector, in academia - having thus a more analytical profile - or in different political positions. In most cases, the designation of regulators is open to political principals and only limited by professional background requirements.

There might not be just a single reason underlying politicians' decisions to create independent regulatory agencies. In fact, the literature offers different arguments to account for this process. Delegation, and in particular, the introduction of mechanisms to protect the independence of regulators' decisions, as in the case of fixed-term mandates, was highly recommended by international organizations and professional associations during the 1990s. Delegation was presented as the "adequate" institutional form for new regulatory agencies (see, for example, OECD, 2000, 2006, or World Bank, 1997) and a necessary condition for the modernization of existing agencies. Suddenly, it became an international standard (Gilardi, Jordana \& LeviFaur 2006, Jordana \& Levi-Faur 2005). When analysing the introduction of independent regulatory agencies, one line of reasoning justifies this innovation as an institutional solution to the credible commitment problem (Kydland \& Prescott 1977, Majone 1997): fixedterm mandates can enhance policy stability and curtail confidence problems arising from short-term interference related to political change (Gilardi 2002). However, a more self-interested interpretation argues that, by introducing delegation mechanisms, politicians intend to strengthen their long-term regulatory goals. The main reason underlying this explanation is that regulators are expected to survive 
their mandate and influence regulatory policy further in the future (Moe \& Caldwell 1994).

Rather than exploring the reasons that underlie politicians' decisions to establish independent regulatory agencies, we intend to discuss the consequences. Therefore, we are interested in examining the de facto independence of regulators in exercising their power. Formal rules of delegation may allow independent decisions by regulators, as they avoid governmental pressures. Still, there is a huge variation in the ways in which these rules are effectively implemented across countries and sectors (Cukierman 1992, Maggetti 2007, Jordana \& Ramió 2010). Consequently, while formal delegation rules are a necessary component to observe when discussing the behaviour of regulators, they are not a sufficient one. Other mechanisms are expected to play a significant role in allowing the de facto independence of regulators.

This article focuses on the personal and professional characteristics of agency board members to see whether they have an impact on the ways in which delegation rules are observed, and whether this happens in practice. If the formal tenure rules are not adhered to, as in the case of early retirements after a political change, regulators do not have the opportunity to behave independently in practice. We thus provide a framework to reveal to what extent board members are linked to politicians and bureaucrats, and to discuss how these links have an influence on their persistence in office. The proxy we are using to assess independence - political vulnerability - has several shortcomings. Certainly, many other reasons not directly related to board members' stability and vulnerability may prevent their independent behaviour in an agency. However, we believe the proxy reveals some fundamentals related to the regulatory process and its predictability. By focusing on regulators' characteristics, we scrutinise 
how this proxy can be better refined when used for quantitative analysis, as for example to avoid "false positives".

Variation in the political affiliation of regulators is important. Thatcher's (2005) findings show that regulatory agency members (publicly affiliated with a political party) have a large number of party links, ranging from 3 percent in Britain, 36 percent in Germany, 46 percent in France to 77 percent in Italy. On the contrary, he finds that before working for the agency many regulators worked within the public sector and this holds true for all four countries. His conclusions suggest that regulators are not very distinct from elected politicians and public servants despite significant variation across countries. Thatcher also shows that the political vulnerability of agencies is low in the above countries and suggests two possible interpretations. Either regulators adjust their actions to the principals' preferences because they fear direct intervention in the agency, or political principals accept the existence of some "agency losses" as the costs of effective intervention and refrain from acting. In either of the two cases there is not a visible conflict that would allow us to make an assessment. Thatcher does not provide an answer to this dilemma of how to assess regulators' independence in practice. He argues that there is a problem of "observational equivalence" as the same evidence - infrequent political intervention - can easily support both options: the actual independence of regulators or their de facto accommodating of political principals (Thatcher 2005: 369).

Our approach aims to overcome this problem by assessing de facto independence. We thus combine our independence proxy with the profiles of regulators. We assess whether board members have a political affiliation or acknowledged ties to parties, and then attempt to determine whether these links affect their persistence in office. If 
formal rules are respected, board members' political ties might be compatible with the fulfilment of fixed-term mandates, and we should not expect accommodation to the preferences of principals. We also observe whether regulators have a background as traditional bureaucrats. In this case, formal rules might be respected, but with some accommodation to the preferences of principals. Bureaucrats acting as regulators would adapt their preferences to the new political party in government to reduce their own vulnerability, thus making the agency de facto non-independent of governmental preferences. Finally, we also identify to what extent board members have a professional profile, being recognized experts in their policy areas. This is an important dimension of regulatory governance as it promotes public policy-making in the light of state-of-the-art scientific knowledge. Such professional capabilities may also have an impact on the fulfilment of formal independence rules, making the fulfilment of fixed-term mandates for all cases more probable, given that triggering early retirements may entail higher political costs.

\section{Regulators: Assessing their Political Vulnerability}

Assessing board members' vulnerability to political changes allows us to quantify the extent to which their tenure cycles are detached from political dynamics. We believe this constitutes a good proxy for measuring the existence of non-hierarchical relationships with politicians. It requires detailed measurement. Although in most cases formal rules establish a fixed term for regulators, they often face the risk of being replaced after a political transition, namely when a new president or prime minister takes office or when a change in the partisan composition of the government occurs, even if their terms of office do not coincide (Hanretty \& Koop 2013). To this aim, we 
introduce a method to measure the de facto separation of board members from political cycles.

The first indexes created to assess agency heads' vulnerability to political changes measured the degree of governments' formal political delegation to central banks (Cukierman 1992). Additionally, Cukierman \& Webb (1995) elaborated an index to measure de facto political delegation based on the rate of turnover of central bank governors, rather than on their formal legal mandates. Although the index evinces some flaws (de Haan \& van't Hag 1995), it is still the most widely used indicator of central banks' independence. This de facto index indicates the degree of effective control exercised by politicians over the direction of central banks. Moving thus beyond existing formal rules for the appointment of governors, Cukierman \& Webb measure de facto delegation, taking the time that governors remain in office as a proxy. The underlying assumption is that extended periods in office make delegation more effective, particularly when governors survive political transitions.

Building on these elaborations, various de facto indexes of regulatory agency political vulnerability have been proposed to capture variation (Maggetti 2007, Jordana \& Ramió 2010, Hanretty \& Koop 2010). They assume that an agency's independence may be jeopardized if politicians flout rules and replace heads and board members at their discretion. In this paper, we deploy two different indicators of agency independence: an adaptation of the Index of Political Vulnerability (IPV, (Cukierman \& Webb 1995)) and the Rolling Adapted Index of Political Vulnerability (RAIPV). In addition, we introduce an index of agency stability: the Turnover Rate (TOR, (Cukierman \& Webb 1995)). 
The IPV is the "fraction of political transitions that are followed promptly by a replacement of the Central Bank governor" (Cukierman \& Webb 1995, 406). Whereas the term "promptly" originally referred to one or six months, current applications of the index concentrate on a six-month period. Given that our study focuses not only on agency heads but on board members as well, we propose an adaptation of the index of political vulnerability to include the latter: the Adapted Index of Political Vulnerability (AIPV). First, we observe the number of changes in agency board members occurring within the first six months after political transition (see Section 4 for the definition of political transition). Then, we compare this with the total number of current appointments when a political transition occurs.

$$
A I P V=\frac{\text { Number of mandates ending within } 6 \text { montls following a political change }}{\text { Numberof alive mandates at the time of a political change }}(1)
$$

We expect higher values of the AIPV to be associated with increased political vulnerability, indicating how political transitions affect regulators' stability. The AIPV can be read simply as the proportion of appointments that end in a particular time against the total number of active mandates by then.

The second indicator of the agencies' political vulnerability is the RAIPV. Given that this index varies by six months, it allows a more refined measure of the effects of political transitions. As in the case of the AIPV, the RAIPV is an aggregate measure and does not relate to specific appointments. To build the index, we employ "rolling windows" of two years (4 periods). The moving means of the AIPV are calculated throughout the whole period and not only for instances of political change. Consequently, the RAIPV at period $p$ corresponds to the mean of the ratio of appointments that end at period $p$ (NME, 
number of mandates ending) with respect to the total number of regulators in office at that period (NAM, number of active mandates).

$$
R A I P V_{p}=\frac{\frac{N M E_{p-4}}{N A M_{p-4}}+\ldots \frac{N M E_{p}}{N A M_{p}}}{5}
$$

Higher values of the RAIPV are associated with increased political vulnerability. Agencies whose heads and board members possess more staying power are expected to be de facto more autonomous. Accordingly, lower values of RAIPV correspond to lower levels of political vulnerability and higher de facto independence.

The last indicator is the TOR taken as the inverse of the time an appointment $(a)$ lasts, measured in years. Hence, if an appointment lasts 4 years, the TOR is $1 / 4=0.25$ and if it lasts 5 years the TOR is $1 / 5=0.2$. Thus, higher values of the TOR indicate a shorter tenure and vice-versa. In this case, no additional adaptation is required to use the index in an environment including board members in different agencies.

$$
\operatorname{TOR}_{a}=\frac{1}{\text { In years, durationof the appo int ment }}
$$

Contrary to both the AIPV and the RAIPV, TOR is not an aggregate measure: it refers to specific appointments so that we can employ particular means for different subgroups. As an indicator, TOR measures the stability of regulators, though it is not an index related to political changes.

These three indicators apply exclusively to appointments made by direct designation, and exclude "appointments by externally held positions", that is to say, appointments to the board automatically produced because of a position held in a particular ministry, public 
agency, business or social organization. For example, in Spain, the general Director of the Treasury is automatically a member of the Central Bank board. We exclude these cases from our analysis because such "automatic" appointments do not require specific designation, while dismissal is also "automatic" when the external position held ends. Making use of these indicators of political vulnerability, and based on the expectations discussed in section 2, we submit a set of four hypotheses. As mentioned, we expect to overcome the problem of "observational equivalence" identified by Thatcher (2005) and to confirm that variations in regulators' bureaucratic or political ties and their professional experience will impact on the prospects of de facto agency independence - according to our expectations. Moreover, through our case study, we aim to examine the relevance of institutional settings to explain differences in the tenure of regulators.

Hypothesis 1 - De facto independence and party dependence: De facto agency independence will be weaker when agency boards include several members having explicit political party links. 
This has been a very common expectation in the normative literature on regulatory agencies. It has often been argued that involving political parties in regulatory agencies would weaken their independence. In contrast, the literature expects that professionals without political interests would experience less interference, assuring the predictability and stability of agencies' activities. To confirm this we expect that the stronger the regulators' links with parties, the higher their political vulnerability. Our assumption is that the party in government will try to curtail the role of political appointees from other parties in agency boards, in particular if they have the majority of the seats in the board, increasing the political vulnerability and reducing the de facto independence of the agency.

Hypothesis 2 - De facto independence and bureaucratic adaptation: De facto agency independence will be weaker when agency board members have civil servant status.

This hypothesis contradicts the measure of low political vulnerably as a proxy for de facto independence. We base our analysis on general considerations about bureaucratic behaviour in democratic settings, formally dependent on political principals. Bureaucrats, socialized in administrative structures of a hierarchical nature, are used to having to adapt to changing political leaderships. To confirm this we expect board members having a bureaucratic background to exhibit less political vulnerability than those lacking such background, to the extent that their normal behaviour would be to avoid potential conflicts with politicians. We thus assume that board members having a bureaucratic background will accommodate to the preferences of the ruling party in case they survive political changes, all of which, in turn, will lead to a decrease in agencies' de facto independence. 
Hypothesis 3 - De facto independence and professional identity: De facto agency independence will be stronger when agency board members have a professional and scientific background.

This hypothesis is also based on conventional expectations in the literature of regulatory agencies. Strong scientific and technical knowledge in regulatory matters empowers those in charge of regulatory decisions, making them less vulnerable insofar as they are more capable of arguing and defending their preferences before politicians. To confirm this we expect agency board members relying on higher professional experience and/or scientific-technical expertise to be less exposed to political vulnerability. We submit that the persistence of professionals with neither strong bureaucratic ties nor political links is less sensitive to political cycles. In these cases, low political vulnerability and completed fixed-term mandates would mean that agency independence is strong in practice.

Through the examination of these three hypotheses, we intend to disentangle under what conditions regulators can act independently in practice, and enjoy a non-hierarchical relation with the government. Finally, we also consider that differences in regulators' political vulnerability relate to existing appointment rules for each agency. As commonly argued in institutionalist approaches, we assume that appointment rules can include both formal and informal mechanisms and that in many cases they combine in the articulation of complex procedures involving party negotiations and governmental and/or legislative decisions. We expect the involvement of the legislature in de jure procedures related to the appointment of regulators to increase the accountability of the process, allowing in turn, for greater de facto independence of board members. 
Hypothesis 4 - De jure and de facto independence: Ceteris paribus, differences in regulators' political vulnerability relate to the institutional design of board appointments.

\section{Regulatory Agencies and Regulators in Spain}

The creation of regulatory agencies in Spain appeared during the 1990s in the context of a large wave of agency diffusion worldwide, but particularly in Europe, as the European Union was then intensively promoting the creation of new regulatory agencies in different sectors. Furthermore, privatization policies in sectors such as telecoms or electricity boosted the establishment of new agencies to supervise the development of the new utilities markets (Jordana, Levi-Faur \& Puig 2006). During the 2000s, agency creation continued in Spain though it concentrated on sectors related to risk prevention (pharmaceuticals and food safety, among others). When delving into the development of the regulatory state, Spain may be considered representative of continental European countries, both in political and administrative terms. Continental European countries group closely together regarding their parliamentary political regimes, their reliance on traditional bureaucracies and administrative law tradition, among other relevant features (Ziller 2007, Peters 2008, Painter \& Peters 2010).

In Spain, a parliamentary democracy, two major parties, (conservative and socialist,) have alternated in office since the establishment of the 1978 Constitution. However, some non-state wide parties were active in a few regions (i.e., nationalist parties in Catalonia, the Basque Country and Galicia), adding more complexity to the country's party-system. Although no formal coalitions have occurred at the national level - because of the lack of an absolute majority for the ruling party - often nationalist parties were involved in 
negotiations and pacts to support minority governments. In this context, patterns resembling constitutional democracy emerged - though not very stable ones - in which social partners were also often involved.

The original database developed for this research contains an innovative component: the units of analysis are both the appointed individuals and the appointments to the agency board. This captures both the fact that some individuals can be appointed successively by more than one agency, or that they can be appointed again by the same agency to fulfil different tenures. A first set of questions provides biographical details of board members. The second dimension relates to particular characteristics of the appointments, including the initial and ending dates, the specific position, the appointment procedure and the reasons underlying the ending of mandates. Finally, a third set of variables looks into regulators' professional profiles, namely, their professional careers before and after the appointment.

The data consist of 448 appointments of 325 individuals in 12 regulatory agencies between 1979 and 2010. We took 1979 as the starting year because the Spanish democratic constitution was approved by referendum in December 1978. Changes in the landscape of regulatory agencies in Spain after 2010 are beyond the temporal scope of this article.

The appendix contains the technical details of the data gathering process, descriptive tables and summaries of the sample. In 1980, there were 29 regulators active in Spanish regulatory agencies' boards in three entities. Ten years later, this figure remained almost unchanged. Nevertheless, the number of active regulators increased to 77 in 2000, reflecting the rapid diffusion of regulatory agencies during the 1990s. The 2000s, however, witnessed a more moderate augmentation of the number of agencies and consequently in the number of board members. 
By the end of 2010, this number - for the 12 agencies identified in that year - reached 125 regulators in office (Figure 1).

[Figure 1 about here]

Figure 2 illustrates this evolution over a period of more than 30 years, showing the temporal progress of the number of board positions available in each regulatory agency. This is a figure of the de jure characteristics of appointments. Disruptions indicate modifications in the number of board members and the selection of rules by a particular agency in a specific year. Bold lines stand for agencies' heads (presidents or governors), whereas grey lines represent the rest of board members (one line for each position). The solid lines represent positions filled by direct appointment, whereas the dashed lines account for the "automatic" appointments related to externally held positions. Based on the agency's internal regulations, these externally held positions refer to those appointments made because of the appointee's position in government or other public entities and which entitle him to become a board member and even, in some cases, to be the agency head (three cases). They constitute a particular type of agency, strongly related to the ministry and relying on larger boards, all of which suggests a more deliberative and consultative nature.

[Figure 2 about here]

Of the 448 appointments identified in our dataset, 66 were "automatic" due to externally held positions. The proportion of board members thus appointed was more than 20 percent (out of 29 positions) in the early 1980 s, but by the late 2000s this percentage dropped to about 10 percent (out of 125 positions) because almost no newly created agency boards included such positions. Obviously, we exclude appointments made because of externally held positions when we examine those potentially vulnerable to political changes. This leads to 382 positions 
resulting from direct appointment between 1979 and 2010. However, not all the occupants of these positions were named for a fixed-term (only 265). In fact, when looking into the 112 positions based on direct appointments in 2010, more than 50 percent lack any provision indicating their term of office.

[Table 1 about here]

The appointment mechanisms of board members vary across regulatory agencies in Spain. In Table 1, we categorized agencies according to their particular appointment procedures. A first one, based on fixedterm appointments by the government and under parliamentary oversight, was adopted by agencies regulating network industries (CME, CNE, CNSP), but also by the competition agency (CNC) and the nuclear safety agency (CSN). Secondly, and though only prevalent in the financial area (BdE and CNMV), there is a procedure that combines a majority of fixed-term appointments made by the government with some "automatic" appointments due to externally held positions. Finally, a third procedure, which rules the appointment of board members in most risk regulation agencies (AGPD, AGEMED, AESAN, AEA and AESA), shows non fixed-term appointments for all board members, and combines some "automatic" appointments with nominations by social representatives and different public entities together with direct appointments by the government.

From an informal point of view, it is worth mentioning a quite extended practice in Spain related to the designation of board members, mainly in agencies operating in financial and network sectors. Since the 1980s, almost all governments have negotiated the designation of these board members with the main opposition parties, and even accepted the inclusion of some individuals suggested by the latter. This, for example, led to the tradition that while the government named the 
president of the Central Bank, the main opposition party suggested the vice-president. Because of this informal procedure the boards of these agencies frequently turned out to be a reflection of the composition of the parliament. However, due to the variable duration of political cycles, on the one hand, and the fixed-term of board members (and non-simultaneous replacement in most cases) on the other, occasionally it was the case that the majority of the agency board did not coincide with the majority of the parliament after a political transition.

This being the case, the potential for conflict between government and agency was significant, given that, though informally, the agency board was named in fact along political lines. This is precisely a question we intend to explore in this paper by examining to what extent early retirements took place in these cases and to discuss under what circumstances they did so, while also taking into consideration the background of agency board members. In fact, during the 2000s, and concurring with cases of non-coincident party majorities in agencies and parliament, some episodes of high tension related to agency governance occurred. As they became publicly known, they acquired high political salience.

For the purposes of our analysis, we have defined a period of political transition as the period from the election until six months after. Thus understood, three main political transitions occurred in Spain between 1979 and 2010, which accounted for 18 months of political change (for a total period of 384 months). In other words, during these 32 years the country lived under political change 18/384=4.7 percent of the time. These political transitions refer to the victory of the PSOE led by Felipe González in 1982, the electoral triumph of the right-wing PP with José María Aznar in 1996, and the 
victory of the PSOE again in 2004, this time under the leadership of José Luis Rodríguez Zapatero.

\section{Results}

Our final sample includes 325 individuals who acted as regulators in agency boards in Spain from 1979 to 2010 . Their mean age at the time of appointment was 52 years and this remains quite stable during all the period considered. Almost all were university graduates, while about 39 percent held a $\mathrm{PhD}$. These basic data indicate that, in most cases, becoming a regulator probably represented the fulfilment of a professional career, often bringing experience and/or academic qualifications to the position. It is worth mentioning the extraordinary incidence of what we describe as the emergence of a "regulatory career". Looking into the data from the individual (not the appointment) point of view, we find that up to 86 individuals were appointed more than once. This group concerned 209 of 448 appointments during the whole period examined. The vast majority of them (63) were appointed only twice, but some three (16 individuals) or four times (4 individuals) and even up to eight times.

\subsection{On the duration of appointments}

The life of appointments refers to the number of days during which an appointment is "active". That is to say, it refers to the period elapsed between the starting date of tenure and the ending of the mandate for various reasons, including the end of the office term, dismissal and death, among others.

Table 2 depicts the minimum, maximum, mean and standard deviation of the appointments, measured in years, for the 448 appointments in our dataset. We also calculate the TOR of the 
appointments based on the 382 appointments included, irrespective of whether these had a fixed term, though we exclude appointments by office held.

[Table 2 about here]

The mean of appointments is close to four years in Spain, though showing great variation as revealed by the large standard deviation, which indicates that the difference is 2.4 years on average. This suggests a map with a high variability in the time span of appointments. When disaggregating our results by nomination procedures, differences become even more obvious. Appointments in which both the government and the legislature participate have much longer periods than those resulting from other procedures. We have also performed a Cox regression to check if appointments differ when including other control variables, only to find that the policy sector and the type of appointment are the two key variables that explain duration in office (not reported here). Individuals appointed by designation experience a lower risk of ending their mandates early than those appointed by office held.

The TOR is a basic measure of agency boards' stability. This measure is the inverse of the average tenure (or the inverse of the life of the appointment) measured in years. The mean in Spain is 0.25, which corresponds to the $1 / 0.25=4$ (3.85) years previously reported as the mean duration of the appointments. A higher TOR means that the appointments have a shorter duration. The Spanish value is very close to that reported for agency heads in a sample of European countries by Hanretty \& Koop (2010), which they found to be 0.24 with a standard deviation of 0.16 . However, to the extent that the standard deviation is 
0.41 in Spain, double that of Europe, the duration of appointments appear to have a rather high variability.

The TOR is very high for appointments made by the government only (particularly in the case of the Stock and Exchange Agency -0.37) and for those agencies including social representatives (i.e. the Food Safety Agency -0.41). On the other hand, the lowest TORs occur in those areas in which both the government and the legislature are involved in the appointment (namely, the Nuclear Safety Commission (0.17), one of the oldest agencies in Spain). What is interesting to note is that the TOR has been increasing in Spain over time: it was 0.20 during the $1980 \mathrm{~s}$, moved to 0.25 in the $1990 \mathrm{~s}$, and reached almost 0.30 in the 2000s.

When we focus only on fixed term appointments, we get a better grip on the reasons underlying this high variability. Available data show that the effective duration of mandates is highly volatile with respect to the expected duration. Figure 3 depicts the histogram of the number of appointments aligned according to the difference between their formal term and their real duration, measured in years. Positive values represent appointments that have lasted longer than expected, whereas negative values stand for mandates ending before due date. Globally, strict compliance with the duration of the mandates is certainly not a characteristic of Spanish regulatory agencies boards. Only 40 percent of regulators end their mandates on the due date (allowing for the fact that under our definition this could be up to six months later). About 15 percent of mandates last longer, about one year or more after their formal expiry date. This may be because of the difficulty of appointing a new board member, especially when this process involves the legislature. However, what is more interesting still is the larger number of cases whose mandate expires before the end of 
the term, and which make up about 45 percent of the total number of cases.

[Figure 3 about here]

To what extent do these early resignations relate to the political vulnerability of board members? This might occur after a political transition when a regulator appointed by the previous government does not remain even if the office-term has not expired yet; but we documented only 17 cases, about 5 percent of all finished appointments. Clearly, this does not seem to be the main reason for early resignations. In the case of Spain, the AIPV for the latest 30 years has been 0.076 . This means that, on average, 7.6 percent of the active appointments end within six months of the transition. However, and even if political vulnerability is not the only reason underlying the early dismissal of regulators, we are particularly interested in unravelling the ways in which political changes impact on their persistence.

\subsection{Political careers}

Building on our first hypothesis, which looks at the relationship between the vulnerability of agencies' board members and their political ties, we first identified the political connections of these individuals by looking into their political involvement before becoming board members. We find that 136 out of 325 individuals in our dataset (41.8 percent) had previous political connections, and accounted for 46 percent of the total number of appointments (196 out of 448). Table 3 presents the percentages of appointments of individuals who lacked connections with political parties, across different nomination procedures. We distinguished between those "weakly" and "strongly" connected. Whereas weak connections only entail party membership or 
public collaboration with a political party (i.e. considered by the media as having a particular party affinity), strong connections mean that the appointee has had earlier public (at political level) positions, has been selected as an electoral candidate by the party or has even been a party officer.

[Table 3 about here]

Our results illustrate that in 44 percent of all appointments, Spanish regulators had clear political ties. Of all those regulators having political ties, one third had strong ties and two-thirds showed weak links. Interestingly, this figure resembles Thatcher's (2005) results when looking into other countries in continental Europe. However, there is wide variation across nomination procedures. In this sense, there is less evidence for political relationships (only 33 percent) when both the government and social representatives share nomination responsibilities. Contrariwise, when looking into nominations involving the government and the legislature, evidence for political ties is stronger (56 percent). When focusing on the duration of those fixedterm regulators having political party links, we find that their mandates end systematically earlier when compared with those lacking such ties, although the differences are not large (see Figure 4). Additionally, only rarely do regulators having political party ties continue their mandate after the established term, while those without party links show a higher probability of remaining in their positions for longer.

Furthermore, Figure 4 can be interpreted as follows. The horizontal axis stands for the difference between de jure and de facto durations of a mandate, therefore negative values represent appointments that ended before their expected termination date. The vertical axis is simply the 
cumulative proportion of appointments. Overall, in a perfect world where all appointments end on the day they are expected to expire, the figure would simply be a vertical line centred at zero. On the other hand, if mandates finished randomly during their duration - being equally likely to finish on the first day of the appointment or many years after - the data points would lay on a 45 degree line.

[Figure 4 about here]

When looking into the AIPV, which allows us to measure political vulnerability more specifically, we observe that regulators having political links show a very low AIPV (0.02), compared with those lacking such links (0.11). It appears that - contrary to what we suggested in Hypothesis 1 - political links are actually a protection against removal after a political change occurs, while not having such ties increases the risks of being removed. Based on this, we can suggest that the de facto independence of agencies is stronger in those cases where regulators enjoy more political links. In fact, regulators with political ties do not show a very different TOR from those without such ties, but are slightly larger ( 0.260 vs. 0.248$)$, all of which entails shorter terms in practice. Additionally, and as we can observe in figure 4, this concentrates in a period close to the end of the formal tenure.

\subsection{Bureaucratic careers}

Moving to our second hypothesis, we expect civil servants appointed as board members of regulatory agencies to weaken de facto agency independence if they exhibit less vulnerability than the rest. We collected data regarding whether the individual was a tenured civil servant at the time of appointment. In fact, out of the 325 individuals in 
our dataset, 144 had public servant status when appointed. Moreover, of the 448 appointments in our sample, 201 (45 percent) were civil servants and 247 (55 percent) were not (note that we add university professors to the non-civil servant category even though these have public servant status in Spain). Thus, we find that individuals who were already civil servants occupied almost half of all positions.

[Table 4 about here]

Interestingly, the percentage of civil servants among regulators shows a large difference, ranging from 57 percent when appointed only by the government, to 35 percent in agencies where nomination included the participation of social representatives (Table 4). For a significant number of these tenured civil servants it could be the case, however, that they were on leave at the time of the appointment and employed in the private sector or in political positions.

When looking into the AIPV, which measures political vulnerability more specifically, we find that civil servants - acting as regulators with a fixed-term - have a lower AIPV (0.061) than non-civil servants, including university professors (0.084). This provides good evidence for Hypothesis 2, regarding the lower political vulnerability of civil servants compared with others. Nevertheless, and given that they show a very similar TOR, civil servants do not necessarily stay longer in office than non-civil servants. There is a slightly higher tendency for non-civil servants to end their mandates on time, when compared with civil servants, though differences remain relatively small (for those appointed for a fixed term). Only university professors show a clear pattern of few early retirements compared with the rest. 


\subsection{Professionals and experts as regulators}

Here we aim to test our third hypothesis: the stronger de facto independence of agencies where regulators have technical expertise and/or a professional background. To this end, we contrast the duration of mandates for those regulators who had a higher education degree (a $\mathrm{PhD}$ ) - including university professors (who should also hold a $\mathrm{PhD}$ ) compared with the rest of regulators. Summing up this group, we might be able to identify a group of professionals and experts within our sample of regulators: whereas not all experts might be counted, those counted can be definitely considered as professionals or experts.

[Figure 5 about here]

The political vulnerability of board members having a $\mathrm{PhD}$, as measured by AIPV, is slightly higher than for non- $\mathrm{PhDs}(0.083$ vs. 0.069), meaning that board members having a $\mathrm{PhD}$ experience a higher risk of early dismissal in political transitions. This result does not support our Hypothesis 3 since we expected expertise to reduce the vulnerability of regulators in political transitions. However, their mandates end on time (or turn out to be longer) in larger proportion than non-PhD regulators: more than 60 percent versus 40 percent for those without $\mathrm{PhD}$. We can observe from the Figures that differences in the duration of their actual tenure are very clear. Evidence seems to be mixed for Hypothesis 3. On the one hand, there is no evidence of a protective effect with respect to political vulnerability. Still, it is clear that regulators with a $\mathrm{PhD}$ follow a distinct path from the rest of regulators in terms of the duration of their mandates: in many cases, they experience longer de facto mandates both before and after the end of term. If we remain closely attached to our proxy for de facto independence based on the level of political vulnerability, we should conclude that board members with higher expertise reduce the de facto 
independence of agencies. However, on the other hand, and looking at the higher predictability of their actual tenure, we might suspect that PhDs do contribute, to some extent, to de facto independence of agencies.

\subsection{Differences by nomination procedures}

For a detailed analysis of the differences observed in political vulnerability across nomination procedures (Hypothesis 4), we make use of the RAIPV while also comparing AIPV values. The RAIPV is the moving average of the ratio of appointments that end in a specific period of months with respect to the active appointments, with a time span of five years. The RAIPV has a mean of 0.11 in Spain for the whole period, which indicates that, on average, about 11 percent of the appointments end every 6 months. However, the evolution of the RAIPV and its behaviour in specific moments of political change appears to be more interesting. Figure 6 shows the evolution of the RAIPV, together with the horizontal lines that represent the moments of political change. It starts in 1981 because it is a moving average based on the last two years, so that 1979 and 1980 cannot be computed.

[Figure 6 about here]

On a general basis, there is a rather stable tendency. Nevertheless, at least three periods are identified. The first one lasts until the PP victory in 1996. A first increase after the socialist victory in 1982 peaked in 1986, then the RAIPV decreases gradually but constantly until the early 1990s, when it goes up. The second period starts with the PP victory in 1996. The RAIPV shows a first local maximum after the second victory of the conservatives when they obtained an absolute majority in 
2000, and a second peak two years after the socialist victory in 2004. The results, then, suggest a visible change in the political vulnerability of regulators after these three periods of political transition, though not immediately after the elections.

[Figure 7 about here]

Differences in political vulnerability for each nomination procedure are relevant. Whereas nominations without legislative involvement have an AIPV of 0.16 (Gov) and 0.09 (Gov/Rep), respectively, agencies where the legislature is involved in the nomination procedures portray a small AIPV of 0.02. Agencies where the government (Gov) appoints board members also show a rather high TOR. In turn, these findings indicate that regulators experienced high levels of political vulnerability and shorter periods of effective mandate. This unstable context means that de jure and de facto agency independence rarely coincide. However, what is still more interesting is the proportion of public servants, whose number is much higher than in other cases.

Figure 7 presents this tendency in a more detailed manner: it depicts the RAIPV by nomination procedure. In cases of Gov/Rep nominations, this index shows higher values between one and three years after political transitions. It appears that regulatory positions are not used as "spoils" immediately after electoral victories, though many are replaced in the medium term. For other nomination procedures, there are some removal peaks before political change occurs, but also after political transitions. However, this does not necessarily take place immediately afterwards. In any case, the RAIPV is higher in those cases where the legislature is not involved. Additionally, and related to 
our fourth hypothesis, evidence seems to confirm that there are significant divergences in the vulnerability of regulators, whereas those agencies where the legislature is involved in appointments show lower vulnerability.

\section{Conclusions}

The paper has looked into the life cycle of Spanish regulators to assess empirically agencies' de facto independence. In so doing, we have mainly assessed how their profiles affect their political vulnerability as a sensitive proxy, but also we observed the actual length of their positions. In terms of the relation between regulators and politicians, we find evidence of a high prevalence of political ties among Spanish regulators: 42 percent of them have clear links with political parties, just as in other continental European countries. As to their status, civil servants are also rather numerous among regulators (45 percent) and many of them simultaneously enjoy clear ties to political parties as well. Moreover, our results provide further evidence for this common pattern across European regulators: high levels of politicization and an abundance of civil servants acting as regulators.

We looked in detail into the variations in the political vulnerability of regulators across time and through the period considered by means of our RAIPV index and analysed of the actual duration of mandates. Building on the observed variations, we discussed which particular profiles make regulators more sensitive to political changes, but also acknowledged explicitly that this proxy may not have the same meaning in all cases.

Results from the Spanish case are quite telling. We rejected one of the hypotheses about regulatory agencies' de facto independence, but confirmed two, and found mixed results for the other. First, and contrary to our expectations, our results show that political ties of 
board members do not undermine the de facto independence of agencies. Regulators having political ties, especially those for whom the legislature was involved in their appointment, tend to survive the government that named them - in larger proportion than board members without such ties. The ruling party does not seem to exert a strong pressure to control regulatory positions immediately after an electoral victory. To the extent that informal rules among major political parties to distribute agencies' board members according to their share of seats in the parliament are respected, these results can be preserved. Thus, Hypothesis 1 is not confirmed given that an increase in the level of politicization of regulators does not increase their political vulnerability after a governmental change. These results suggest that regulators' political ties contribute to agency de facto independence, while a completely de-politicized agency may result in a more fragile institution. However, further research is necessary to distinguish those cases in which a new government has the capacity to make new appointments and modify majorities within the agency board from those in which the majority remains different from government.

Hypothesis 2 is confirmed, as we find that civil service status makes board members less vulnerable to political changes. However, that being the case, we do not expect this to be a proxy for agencies being de facto independent, but rather that they will tend to be more accommodative to political principals as they attempt to minimize conflict (though, the final outcome will obviously depend on the number of bureaucrats on the agency board).

As to Hypothesis 3, we found that board members having a $\mathrm{PhD}$ are more politically vulnerable than non-PhDs in the Spanish case. In turn, this means that so far results do not support a positive role of de facto independence for this variable. However, we also found that high 
professionalism contributes to a lower turnover of regulators before the end of their fixed terms. This provides, hence, some evidence regarding the role of professionalism in strengthening de facto independence if we understand this as also including the predictability of mandates, at least for the case of experts and professionals.

In addition, holding all other variables constant, there are significant differences in the political vulnerability of regulators according to nomination procedures (confirming thus Hypothesis 4). Those agencies where the legislature is involved in agency board appointments exhibit larger de facto independence compared with agencies having other nomination procedures. They show a very low TOR and a null AIPV as well, all of which indicates a quite stable institutional environment. While there are only a few board members enjoying public servant status, there is a significant number of professionals and experts. At the same time, these board members exhibit high levels of political links, nearly 80 percent (partly because according to the informal rules, political parties in parliament propose them as candidates). Nevertheless, their low level of political vulnerability suggests that they are capable of acting independently, not necessarily following politicians' preferences despite their continuous connections and linkages.

In this paper, we have provided new insights into the ways in which regulators are embedded within political and bureaucratic elites, and highlighted the essential role of political arrangements in allowing agencies to regain de facto independence. Still, this is not necessarily intentional. For example, the emergence of informal rules among political parties for board member appointments, in interaction with other nomination rules, strengthened the de facto independence of regulatory agencies in Spain (the frequent minority governments also 
contributed). Additionally, we observe the relevant role of the legislature's involvement in nominations as it contributes to the reduction of the political vulnerability of agency board members. Additionally, we suggested that agencies dominated by bureaucratic elites may suffer less political vulnerability, but we do not expect this to be a proxy for de facto independence, because in fact they can adjust to political changes. Professionals and experts in agency boards would provide more predictability, but as we observed their capabilities do not provide them with a shield in times of political transition.

Our analysis of the de facto independence of regulatory agencies has combined the use of the political vulnerability proxy and other measures of regulators' security of tenure, with the identification of their key personal characteristics. By putting into the discussion both dimensions, we proposed some focused hypotheses that intended to move forward the quantitative assessment of regulatory agencies' independence. We tried to escape from most criticisms of the use of political vulnerability indexes as a way to assess agency independence, in particular, how to distinguish actual de facto independence from the de facto accommodation of regulators to new political rulers. However, we recognise that both proxies and our enhanced framework are still rather imperfect measures of agencies' de facto independence. Furthermore, the concept of de facto independence itself is not easy to disentangle, beyond some basic intuitions. However, we believe our framework offers fertile ground for further disentangling how regulatory agencies' independence is constructed Additionally, we expect our analysis to enrich continuing reflections of the important methodological and conceptual difficulties in measuring de facto independence and the need for a more nuanced interpretation of agency independence in the academic literature. In this sense, and building on our findings, an issue worth investigating is whether the patterns 
observed in the Spanish case occur in other countries, if the methodological tools introduced here are used. In sum, a theory on agencies' de facto independence is still required.

\section{Acknowledgements}

This study was funded by a research grant of the Escola d'Administració Pública de Catalunya (GAP/2944/2010). Support from the Spanish Ministry of Science and Innovation (CSO2009/11053) is acknowledged. We appreciate Nicole Jenne's assistance in the initial stage of the data collection.

\section{References}

Bianculli, A., Fernández-i-Marín, X. \& Jordana, J. (2013). The world of regulatory agencies: Institutional varieties and administrative traditions. Jerusalem Working Paper in Regulatory Governance, \# 58

Cukierman, A. (1992). Central bank strategy, credibility, and independence: Theory and evidence, MIT Press, Cambridge, MA.

Cukierman, A. \& Webb, S. B. (1995). Political influence and the central bank: International evidence, The World Bank Economic Review 9: 397-423.

de Haan, J. \& van't Hag, G. J. ( 1995). Variation in central bank independence across countries: Some provisional empirical evidence, Public Choice 85: 335-351. Gilardi, F. (2002). Policy credibility and delegation to independent regulatory agencies: A comparative empirical analysis, Journal of European Public Policy 9(6): 873-893. 
Gilardi, F. (2008). Delegation in the Regulatory State. Independent Regulatory Agencies in Western Europe, Edward Elgar, Cheltenham, UK.

Gilardi, F., Jordana, J. \& Levi-Faur, D. ( 2006). Regulation in the age of globalization: The diffusion of regulatory agencies across Europe and Latin America, in G. Hodge (ed.), Privatization and Market Development, Edward Elgar, Cheltenham, UK, pp. 127147.

Hanretty, C. \& Koop, C. (2012). Measuring the formal independence of regulatory agencies, Journal of European Public Policy 19(2):198216

.Hanretty, C. \& Koop, C. (2013). Shall the law set them free? The formal and actual independence of regulatory agencies, Regulation \& Governance 7(2): 195-214.

Jordana, J. \& Levi-Faur, D. (2005) . The diffusion of regulatory capitalism in Latin America: Sectorial and national channels in the making of new order, Annals of the American Academy of Political and Social Sciences 598: 102-124.

Jordana, J., Levi-Faur, D. \& Fernández-i-Marín, X. (2011). The global diffusion of regulatory agencies: Channels of transfer and stages of diffusion, Comparative Political Studies 44(10): 1344-1369.

Jordana, J., Levi-Faur, D. \& Puig, I. ( 2006). The limits of Europeanization: Regulatory reforms in the Spanish and Portuguese telecommunications and electricity sectors, Governance: An International Journal of Policy, Administration, and Institutions 19(3): 437-464. 
Jordana, J. \& Ramió, C. (2010). Delegation, presidential regimes, and Latin American regulatory agencies, Journal of Politics in Latin America 2(1): 3-30.

Jordana, J. \& Sancho, D. (2004). Regulatory designs, institutional constellations and the study of the regulatory state, in J. Jordana \& D. Levi-Faur (eds), The Politics of Regulation. Institutions and Regulatory Reforms for the Age of Governance, Edward Elgar, Cheltenham, UK.

Kydland, F. E. \& Prescott, E. C. ( 1977). Rules rather than discretion: The inconsistency of optimal plans, Journal of Political Economy 85: 473-491.

Maggetti, M. (2007). De facto independence after delegation: A fuzzyset analysis, Regulation \& Governance 1(4): 271-294.

Majone, G. (1997). Independent agencies and the delegation problem: Theoretical and normative dimensions, in B. Steuenberg \& F. van Vught (eds), Political Institutions and Public Policy, Kluwer Academic Publishers, Dordrecht, pp. 139-156.

Moe, T. M. \& Caldwell, M. (1994). The institutional foundations of democratic government, Journal of Institutional and Theoretical Economics 150: 171-195.

OECD (2000). Telecommunications regulations: Institutional structures and responsibilities, Technical report, OECD, Paris. DSTI/ICCP/TISP(1999)15/FINAL.

OECD (2006). Telecommunications regulatory institutional structures and responsibilities, Technical report, OECD, Paris. DSTI/ICCP/TISP(2005)6/FINAL. 
Painter, M. \& Peters, B. G. (2010). The analysis of administrative traditions, in M. Painter \& B. G. Peters (eds), Tradition and Public Administration, Palgrave, UK.

Peters, B. G. (2008). The Napoleonic tradition, International Journal of Public Sector Management 21: 118-132.

Thatcher, M. (2005). The third force? Independent regulatory agencies and elected politicians in Europe, Governance: An International Journal of Policy, Administration and Institutions 18(3): 347-373.

World Bank (1997). The private sector in infrastructure: Strategy regulation and risk, Technical report, World Bank, Washington, D.C.

Ziller, J. (2007). The continental system of administrative legality, in B. Peters \& J. Pierre (eds), Handbook of Public Administration: Concise Paperback Edition, SAGE Publications. 
Figure 1: Number of active regulators, Spain, 1979-2010

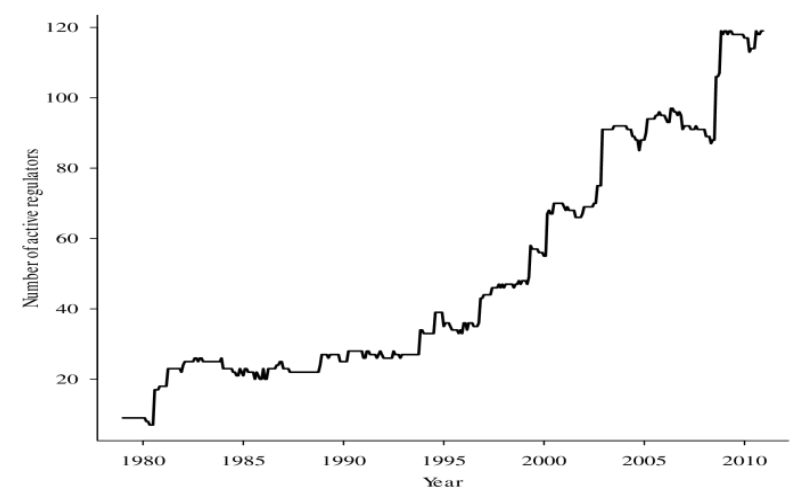


Figure 2: De jure positions in regulatory agencies' boards, Spain, 1979-2010

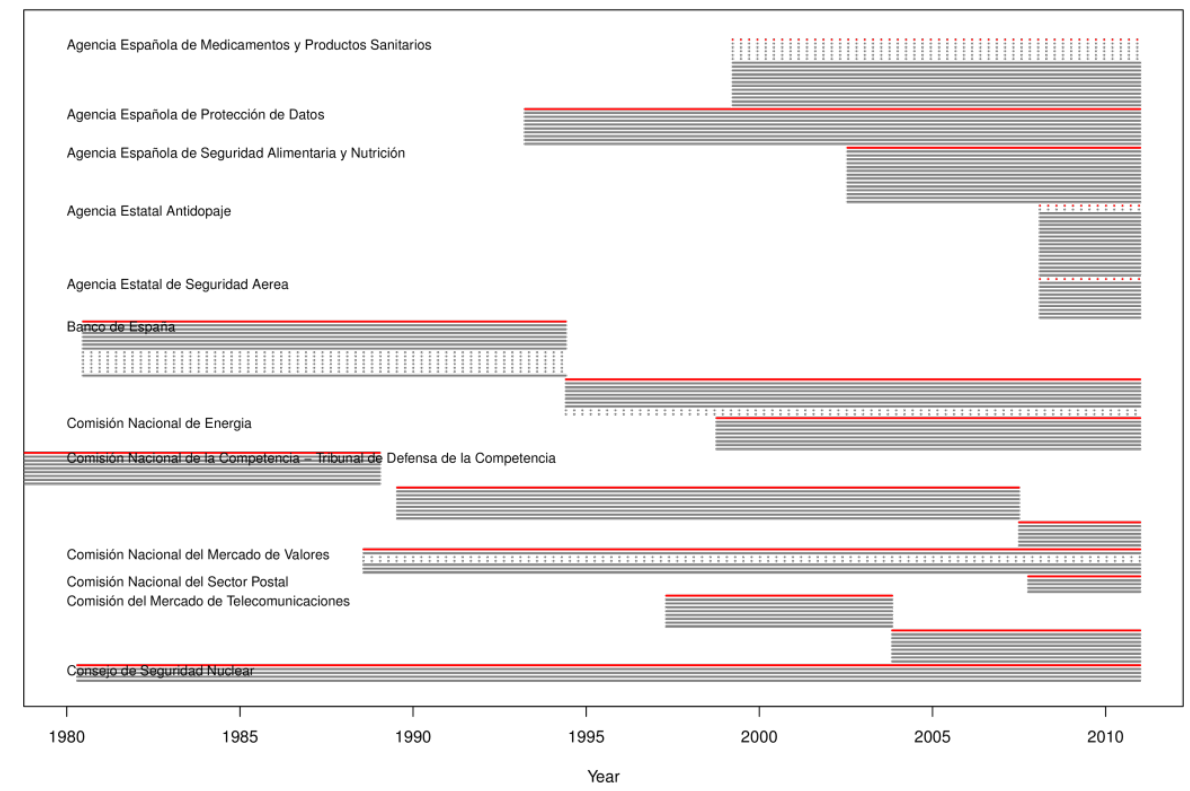


Figure 3: Differences between de jure and de facto durations of the appointments having a fixed-term mandate

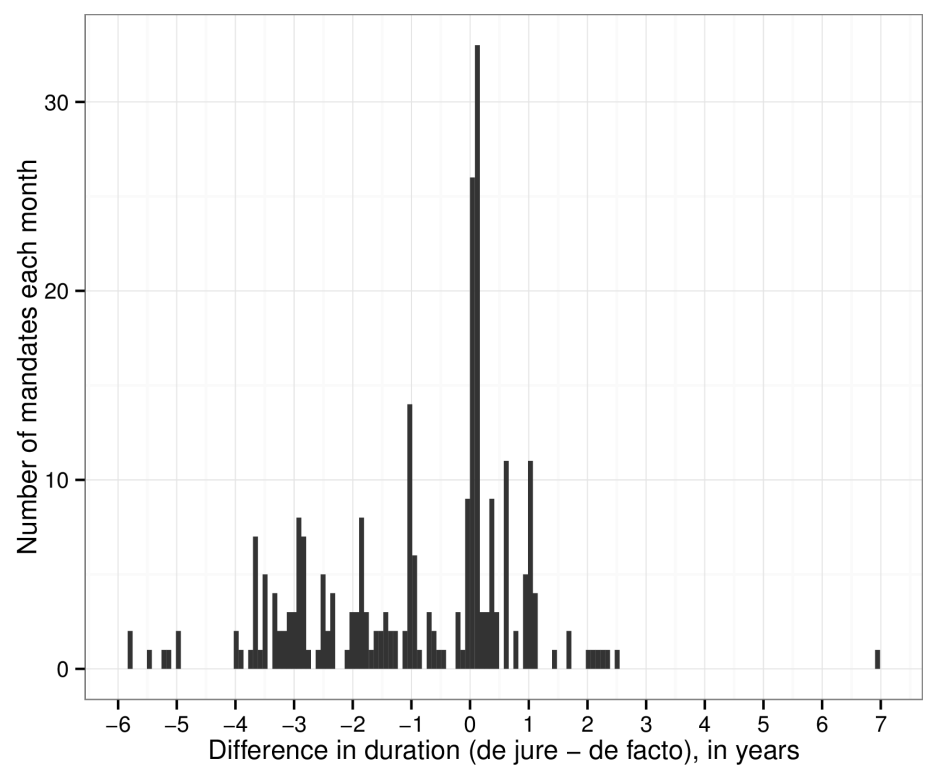


Figure 4. Cumulative plot of the ending of mandates, by political relationship

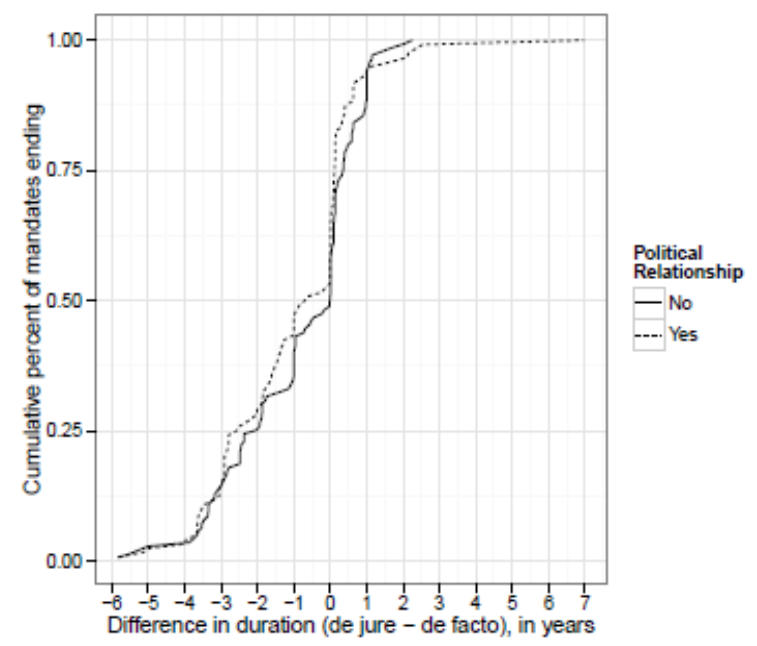

Note: Difference between de jure and de facto durations of the appointments by designation (excluding by office held) and having a fixed mandate. 
Figure 5 - Cumulative plot of the ending of mandates, by PhD

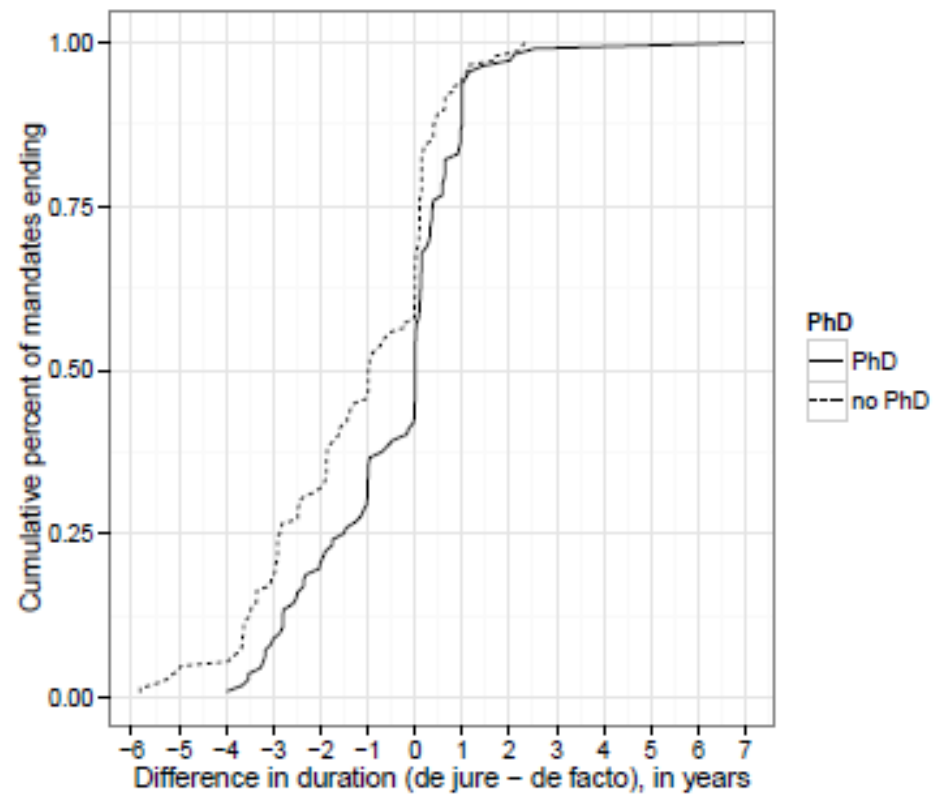

Note: Difference between de jure and de facto durations of the appointments made by designation (excluding by office held) and having a fixed mandate. 
Figure 6: Rolling Adapted Index of Political Vulnerability (RAIPV)

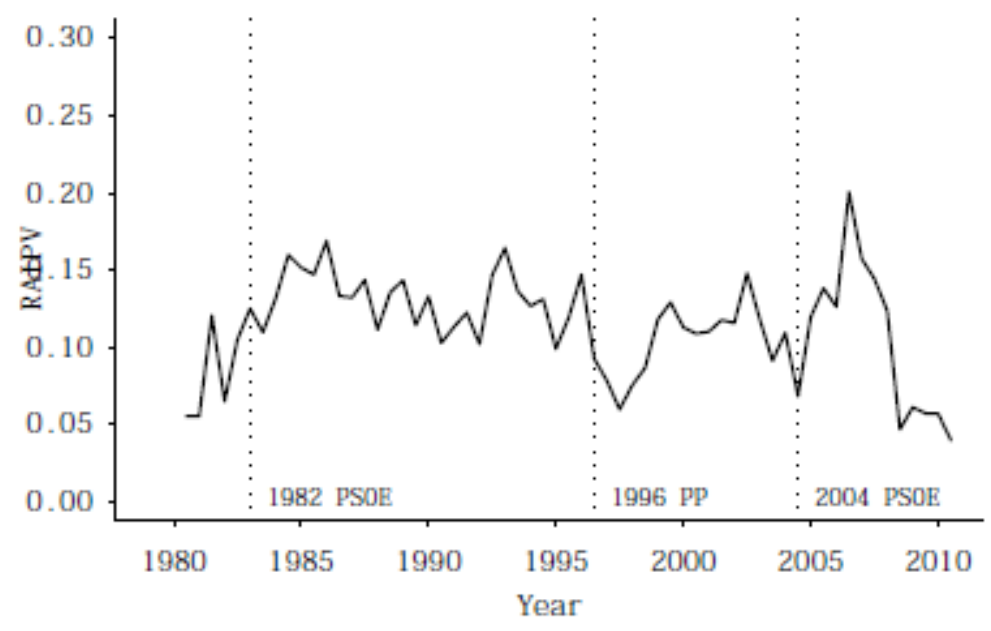

Note: Appointments made by designation (excluding by office held), Spain, 1979-2010 
Figure 7: Rolling Index of Political Vulnerability (RAIPV), by nomination procedures

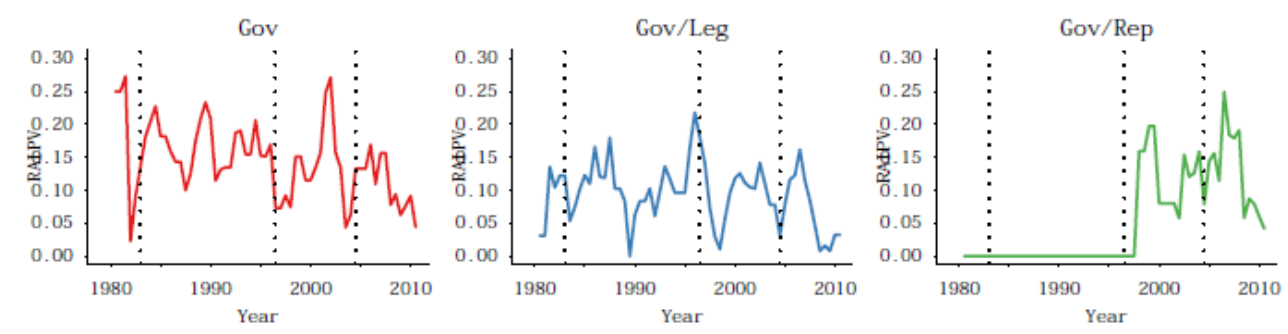

Note: Appointments by designation (excluding by office held), Spain, 1979-2010. 
Table 1: Regulatory agencies in Spain

\begin{tabular}{|c|c|c|c|c|c|}
\hline$\overline{\text { Agency }}$ & $\begin{array}{l}\text { Year of } \\
\text { creation } 1\end{array}$ & $\begin{array}{l}\text { Board } \\
\text { embe }\end{array}$ & $\begin{array}{l}\text { Nominatior } \\
\text { procedure }\end{array}$ & Term & $\begin{array}{l}\text { Total } \\
\text { Appt. }\end{array}$ \\
\hline Bank of Spain (BdE) & $\begin{array}{c}1921 \\
(1994)\end{array}$ & 10 & Gov & Fixed & 81 \\
\hline National Competition & 1963 & 7 & Gov-Leg & Fixed & 63 \\
\hline Commission (CNC) & (2007) & & & & \\
\hline $\begin{array}{l}\text { Nuclear Safety Council } \\
(\mathrm{CSN})\end{array}$ & 1980 & 5 & Gov-Leg & Fixed & 27 \\
\hline $\begin{array}{l}\text { Stock Markets National } \\
\text { Commission (CNMV) }\end{array}$ & 1988 & 7 & Gov & Fixed & 42 \\
\hline $\begin{array}{l}\text { Spanish Data Protection } \\
\text { Agency (AGPD) }\end{array}$ & 1993 & 10 & Gov-Rep & $\begin{array}{l}\text { Not } \\
\text { Fix }\end{array}$ & 49 \\
\hline $\begin{array}{l}\text { Telecommunications Market } \\
\text { Commission }(\mathrm{CMT})\end{array}$ & 1996 & 9 & Gov-Leg & Fixed & 26 \\
\hline $\begin{array}{l}\text { Energy National } \\
\text { Commission (CNE) }\end{array}$ & $\begin{array}{c}1994 \\
(1998)\end{array}$ & 8 & Gov-Leg & Fixed & 21 \\
\hline $\begin{array}{l}\text { Spanish Medicines and } \\
\text { Sanitary Products Agency } \\
\text { (AGEMED) }\end{array}$ & 1997 & 18 & Gov-Rep & $\begin{array}{l}\text { Not } \\
\text { Fix }\end{array}$ & 53 \\
\hline $\begin{array}{l}\text { Spanish Food Safety and } \\
\text { Nutrition Agency (AESAN) }\end{array}$ & 2001 & 16 & Gov-Rep & $\begin{array}{l}\text { Not } \\
\text { Fix }\end{array}$ & 50 \\
\hline $\begin{array}{l}\text { Anti-doping State Agency } \\
\text { (AEA) }\end{array}$ & 2008 & 16 & Gov-Rep & $\begin{array}{l}\text { Not } \\
\text { Fix }\end{array}$ & 19 \\
\hline
\end{tabular}


Aerial Security State Agency 2008 (AESA)

National Commission of the $2007 \quad 5 \quad$ Gov-Leg Fixed 5 Postal Sector (NSP)

Fix
12 Gov-Rep Not 12

Source: Own elaboration

Note: Year of creation (major reforms in brackets), board members (in 2010 , including head of agency), area of regulation and total number of appointments since creation. Nomination procedures: Gov (only government); Gov-Leg (government and legislature oversight), and Gov-Rep (government and social representatives). 
Table 2: Descriptive statistics and TOR of the life of appointments, in years

\begin{tabular}{lcccc|c}
\hline & Min & Mean & Sd & Max & TOR \\
\hline Gov/Leg & 0,2 & 5,1 & 3,1 & 18,0 & 0.20 \\
Total & 0,1 & 3,8 & 2,4 & 18,0 & 0.25 \\
Gov & 0,1 & 3,3 & 1,6 & 10,0 & 0.30 \\
Gov/Rep & 0,3 & 3,0 & 1,5 & 5,3 & 0.32 \\
\hline
\end{tabular}

Source: Authors' dataset on Spanish regulators

Note: Descriptive statistics are calculated using all appointments, while the TOR is calculated excluding appointments by office held. 
Table 3: Percentage of appointments whose individuals have political relationships; Spain, total, and by nomination procedure

\begin{tabular}{lccc}
\hline & Collaboration & Responsibilities & $\begin{array}{c}\text { No evidence of } \\
\text { relationship }\end{array}$ \\
\hline Gov/Rep & 0.16 & 0.19 & 0.66 \\
Total & 0.28 & 0.16 & 0.56 \\
Gov & 0.33 & 0.11 & 0.56 \\
Gov/Leg & 0.39 & 0.17 & 0.44 \\
\hline
\end{tabular}

Source: Authors' dataset on Spanish regulators 
Table 4: Appointments of individuals having civil servant status; percentage, Spain, total, and by nomination procedure

\begin{tabular}{lccc}
\hline & Civil Servant & University Professor & No Civil Servant \\
\hline Gov/Rep & 0.35 & 0.25 & 0.40 \\
Gov/Leg & 0.47 & 0.17 & 0.36 \\
Total & 0.45 & 0.23 & 0.32 \\
Gov & 0.57 & 0.28 & 0.15 \\
\hline
\end{tabular}

Source: Authors' dataset on Spanish regulators 